\title{
MERMIS PARASITISM IN SOME AUSTRALIAN AND MEXICAN ANTS
}

\author{
By William Morton WheEler
}

Harvard University, Cambridge, Mass.

Since reviewing in several former papers ${ }^{1}$ the modifications induced in ants by Nematode worms of the genus Mermis, I have obtained mermithized specimens of four additional species. Three of these are from Australia, a continent from which no cases of this form of parasitism had been previously recorded. The fourth case, from Mexico, partially bridges a gap in the known distribution of antmermithization extending from New England and Colorado to Argentina. In the Old World no cases are known from Asia, Indonesia and Papua, but their occurrence in these regions will be revealed in all probability by examination of sufficient material.

\section{Myrmecia forficata Fabr.} var. rubra Forel

While I was visiting Mr. John Clark in Melbourne, Victoria, during December, 1931, he presented me with a dried mermithogyne of this large Ponerine ant and informed me that he had seen others. The specimen was taken at Belgrave, Victoria, Jan. 29. It has the appearance of a normal deälated female, but the gaster is unusually voluminous and the postpetiole is very broad, being nearly twice as wide as long. Although the thorax is of the normal female struc-

${ }^{1}$ W. M. Wheeler, Mermis Parasitism and Intercastes among Ants, Journ. Exper. Zoölogy 50, 1928, pp. 165-237, 17 figs.; A Camponotus Mermithergate from Argentina, Psyche 36, 1929, pp. 102-106, 1 fig., and Two Mermithergates of Ectatomma, ibid. 37, 1930, pp. 48-54, 1 fig. 
ture, I can find no evidence that the specimen has ever borne developed wings. The tegulæ are normal, but each fore wing is represented by a small, hard, jet-black tubercle. There is no trace of a hind wing on the left side, but the right hind wing appears to be represented by a minute rounded tubercle near the lateral border of the metanotum. If my interpretation is correct, we may suppose that the reducing effect of the Mermis on the wings is very much greater in Myrmecia than it is in the mermithogynes of Lasius, which have these appendages merely reduced to about half or one-third their normal size.

I have not seen the normal female of rubra, which is described by Clark as very slightly larger than the worker $(19-23 \mathrm{~mm}$.) as contrasted with the female of the typical $M$. forficata Fabr., which is considerably larger than its worker. I therefore compare the dimensions of the mermithogyne with those of the females of the very closely related forficata, lucida Forel and regularis Crawley. A lucida female from Hobart, Tasmania (G. H. Hardy) measures nearly $20 \mathrm{~mm}$., its gaster $6 \mathrm{~mm}$. in length and nearly $4 \mathrm{~mm}$. in dorsoventral diameter, the head including the mandibles $6.5 \mathrm{~mm}$., in diameter through the eyes $4 \mathrm{~mm}$. Normal females of forficata from New South Wales and Victoria measure about $22 \mathrm{~mm}$., the gaster nearly $7 \mathrm{~mm}$., dorsoventrally nearly $4 \mathrm{~mm}$., the head including the mandibles 6 $\mathrm{mm}$., through the eyes $3.8 \mathrm{~mm}$. The average female of regularis from Southwestern Australia measures 18-19 $\mathrm{mm}$. in length; gaster $6 \mathrm{~mm}$., dorsoventrally $3.5 \mathrm{~mm}$.; head with mandibles $6 \mathrm{~mm}$., through the eyes nearly $4 \mathrm{~mm}$. The rubra mermithogyne measures nearly $24 \mathrm{~mm}$.; its gaster 9 $\mathrm{mm}$., dorsoventrally $5.5 \mathrm{~mm}$.; the head with mandibles 6 $\mathrm{mm}$., through the eyes $3.6 \mathrm{~mm}$. This specimen therefore shows little modification as the result of parasitism compared with normal females of the closely allied species, except in the greater size of the postpetiole and gaster and its almost complete aptery. Probably, however, the head and thorax are distinctly narrower than in the unparasitized rubra female. The extreme, red bases of the gastric segments are exposed and through them portions of a coiled Mermis are distinctly discernible. 
Camponotus (Tanæmyrmex) consobrinus Erichson

(Fig. 1)

The synonymy of this common and widely distributed Australian Camponotus, which comprises several subspecies and varieties and constitutes a well-defined group in the subgenus Tanæmyrmex, has been confused through failure to recognize the type. This was supposed to be $C$. nigriceps F. Smith (1858), but recently Mr. John Clark has been able

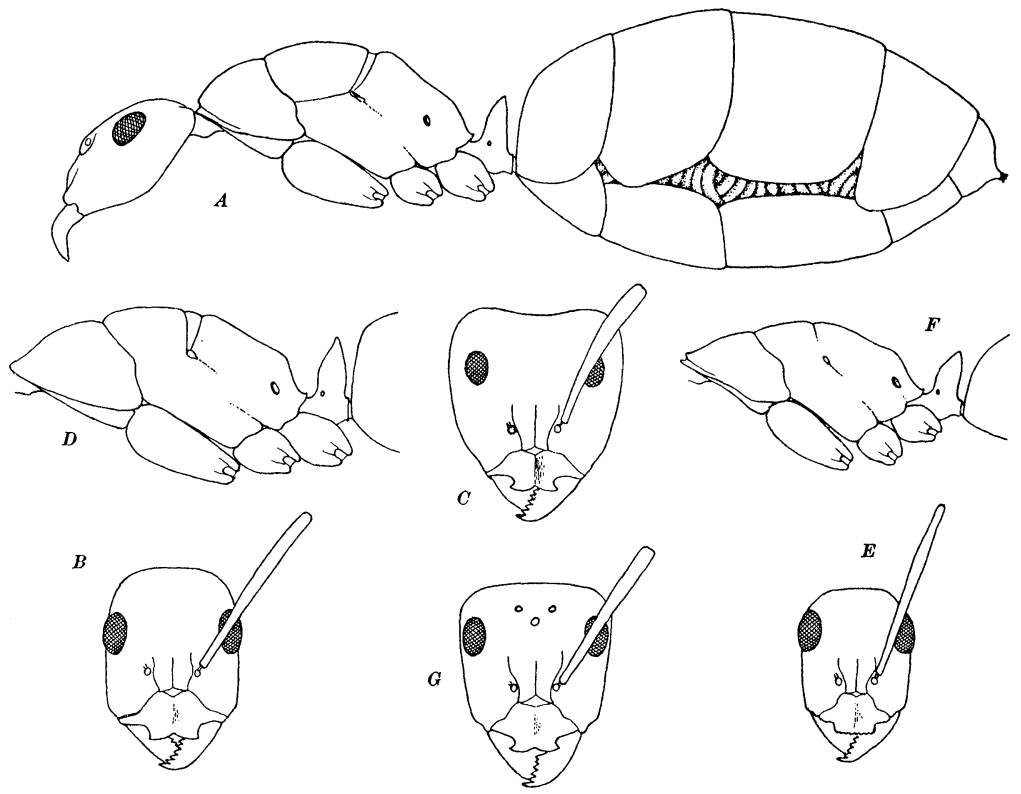

Fig. 1. Camponotus (Tancmyrmex) consobrimus Erichson. A, mermithergate (specimen $\mathrm{g}$ ), in profile; $B$, head of same, dorsal view; $C$, head of worker maxima, dorsal view; $D$, thorax and petiole of same, in profile; $E$, head of worker minima, dorsal view; $F$, thorax and petiole of same, in profile; $G$, head of female, dorsal view.

to identify Erichson's consobrinus, which was described as early as 1841. He has therefore suggested the following arrangement of the various subspecies and varieties to replace Emery's arrangement in the "Genera Insectorum." 
C. (T.) consobrinus Erichson (1841). Type locality: Tasmania (=dimidiatus Roger, 1858). Common in New South Wales and Queensland.

var. obniger Forel (1902). New South Wales.

var. perthianus Forel (1915). Western Australia.

Subsp. lividipes Emery (1887). New South Wales.

(= prostans Forel, 1907).

Subsp. nigriceps F. Smith (1858). Southeastern, South and Western Australia.

var. pallidiceps Emery (1887). New South Wales. (= var. clarior Forel, 1902). Western Australia.

I have taken all of the six valid forms of consobrinus in various localities. They nest in open places in the soil under large flat stones, often in rather populous colonies. The largest workers are not very aggressive. Like many of the other Australian Camponoti they are often common in restricted areas and, like many other species of Tanæmyrmex, seem all to be nocturnal foragers.

In four colonies of the typical C. consobrinus (dimidiatus) among about 20 which I examined on December 14 and 15, 1931 at the Creel, (alt. $3000 \mathrm{ft}$.) at the base of Mt. Kosciusko, N. S. W., eight mermithergates were taken. Each of two colonies contained only one, one colony contained two and another four of the parasitized individuals. Owing to their large size and swollen gasters they were conspicuous among their normal sisters in the superficial galleries of the nests and were quite as alert in escaping when the stones were overturned. The colonies also contained considerable brood, a few males and immature winged females. Dr. P. J. Darlington has recently brought me a ninth mermithergate of consobrinus, which he took March 16, 1932, with a portion of the colony in the McPherson Range, below the National Park in Queensland.

The following are the average measurements (total length and length of gaster) of alcoholic material of the three normal worker forms of consobrinus:

Maxima: Length 13-14 mm.; gaster 4-5 mm.

Media: Length $10-11 \mathrm{~mm}$.; gaster $3-3.5 \mathrm{~mm}$.

Minima: Length 8-9 mm.; gaster 2.5-3 mm. 
The nine mermithergates (in alcohol), which I designate by letters ( $i$ being the specimen from Queensland), had the following dimensions:

(a) Length $12 \mathrm{~mm}$; gaster $6.5 \mathrm{~mm}$.

(b) Length $14 \mathrm{~mm}$; gaster $7 \mathrm{~mm}$.

(c) Length $15 \mathrm{~mm}$.; gaster $6 \mathrm{~mm}$.

(d) Length $15 \mathrm{~mm}$; gaster $7 \mathrm{~mm}$.

(e) Length $15 \mathrm{~mm}$.; gaster $7 \mathrm{~mm}$.

(f) Length $15.8 \mathrm{~mm}$.; gaster $7.5 \mathrm{~mm}$.

(g) Length $16 \mathrm{~mm}$; gaster $6.5 \mathrm{~mm}$.

(h) Length $16.7 \mathrm{~mm}$; gaster $8 \mathrm{~mm}$.

(i) Length $18 \mathrm{~mm}$; gaster $9 \mathrm{~mm}$.

With the exception of (c) and (d), all the specimens have the gaster so greatly distended with Mermis that the white intersegmental membranes are more or less exposed; the two exceptions seem to have lost their Nematodes, though their gasters are decidedly enlarged. It will be seen that, with the exception of (a) and (b), all the specimens are longer than the largest normal maxima workers. Yet all have the aspect of large minima workers with abnormal gastric distension. Closer examination, however, shows that they represent a distinct intercaste, in the sense in which I used that term in my paper of 1928 , because, while the head is much like that of the minima, the thorax and petiole are clearly of the media and maxima type. The head is somewhat broader than in the smallest minimæ and in several of the specimens less smooth and more sharply shagreened, and all have a faint pit in the place of the anterior ocellus. These are characters of the normal maxima. Specimen (i), however, has three very distinct ocellar pits. The clypeal carina, well-developed in all the normal worker castes, is undeveloped in the mermithergates and reduced to a blunt, elongate, median boss as in the normal female. The sides of the head are also distinctly less convex than in the minima and therefore more like the conditions in the female. The thorax is like that of the maxima, being stouter through the pronotum, higher and more convex in profile, with the epinotum proportionally shorter and more rounded, with less distinct base and declivity than in the 
minima. The lateral suture of the mesonotum, which is absent in the maxima but well-developed in the female, is distinct in specimens (b), (e), (g) and (i) and faintly indicated in some of the others. There is a distinct though small metanotal sclerite like that of the maxima (absent in the minima), and the foveolæ on the pronotum are also stronger and more numerous as in that caste. In two of the
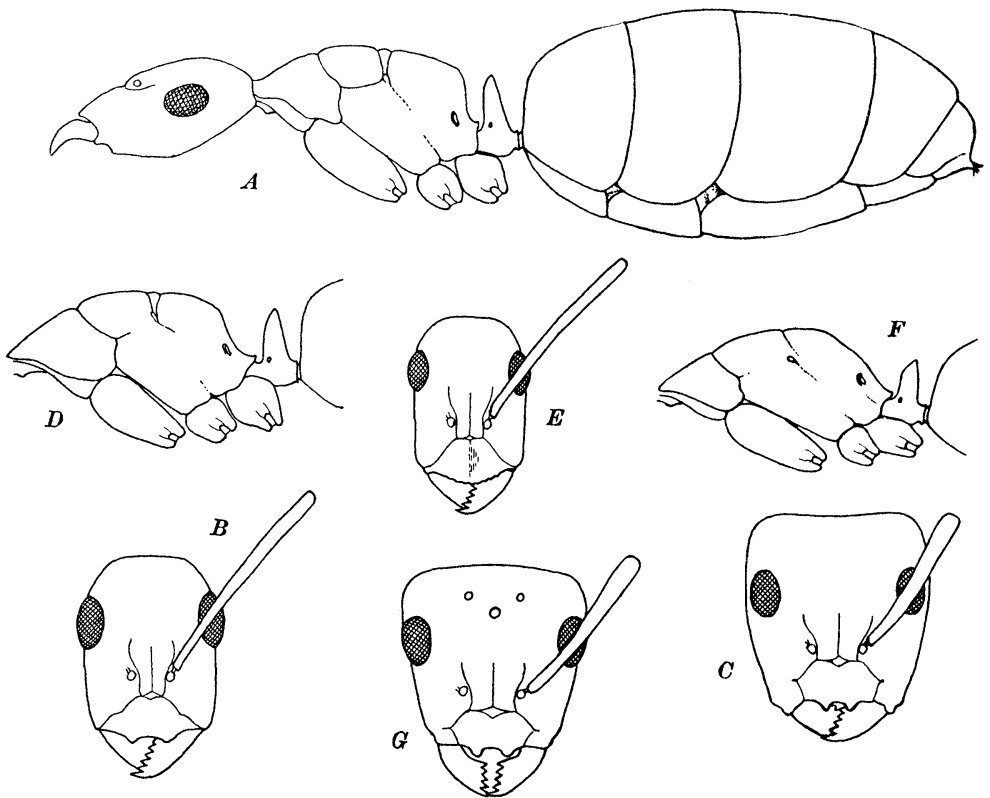

Fig. 2. Camponotus (Myrmophyma) claripes Mayr subsp. piperatus subsp. nov. $A$, mermithergate, in profile; $B$, head of same, dorsal view; $C$, head of worker maxima, dorsal view; $D$, Thorax and petiole of same, in profile; $E$, head of worker minima, dorsal view; $F$, thorax and petiole of same, in profile; $G$, head of female, dorsal view.

mermithergates, (b) and ( $\mathrm{g}$ ), the metanotum is decidedly larger and broader than in the normal maxima and therefore more as in the female. In $(\mathrm{g})$ even the scutellum of the latter seems to be indicated by faint lateral impressions but not by a suture marking it off from the mesonotal scutum. The petiole of all the mermithergates is like that 
of the normal media and maxima in being stouter, broader and with more broadly rounded apical border than in the minima. In $(\mathrm{h})$ this border is even very feebly emarginate in the middle as in some maximæ. The coloration and pilosity of all the mermithergates is that of the normal maxima, media and minima, except (d) and (h), which have the posterior corners of the head red.

Camponotus (Myrmophyma) claripes Mayr. (Fig. 2)

$C$. claripes is one of the most variable and widely distributed of the Australian Camponoti. It is an inoffensive ant which lives in the soil under stones and logs in rather small colonies. According to my observations, the worker media is either extremely rare or nonexistent, as in many species of the subgenus Colobopsis, so that the worker caste is sharply divided into minimæ and maximæ. Since the typical claripes was described by Mayr in 1876 from Peak Downs, Queensland, seven subspecies and varieties have been added by Forel, Viehmeyer and Crawley, but the material in my collection shows that these by no means exhaust the existing variants. Although the species needs revision, I here describe only one of the hitherto unrecorded forms, because it yielded a mermithized specimen.

\section{Camponotus (Myrmophyma) claripes Mayr} subsp. piperatus subsp. nov.

Worker maxima. Length $8-10 \mathrm{~mm}$.

Head shaped as in the typical claripes, but with slightly more convex sides; thorax shorter and higher, especially at the epinotum, which has a much steeper concave declivity, distinctly longer than the convex base. Punctures on the subopaque clypeus and cheeks smaller, more superficial and not elongated. Pilosity as in the type, but somewhat less abundant on the cheeks. Color brownish ivory yellow, legs paler; tip of gaster, a band across each of its more anterior segments, apex of the petiolar node, epinotum, sides of the mesonotum and more or less of the dorsal surface of the head brown or dark brown, the pronotum and paler portions 
of the gaster spotted with brown; tips of mandibles, antennal funiculi, tarsi, knees and tips of tibiæ, clypeus, gula, corners of the head, and a broad transverse band on each cheek yellowish or brownish red.

Worker minima. Length 4-6 $\mathrm{mm}$.

Smaller than the minima of the typical claripes, with distinctly broader head and shorter and more convex thorax, the base of the epinotum more rounded and less distinctly marked off from the declivity. Ivory yellow, legs somewhat paler and more whitish; mandibles, funiculi, tarsi, knees and tips of tibiæ reddish; posterior third or fourth of the head, dorsal border of petiole and two last segments of the gaster dark brown; each of the gastric segments with a narrow posterior brown fascia, the remainder of its dorsal surface and that of the thorax spotted with brown.

Female. Length 11-12 mm.

Closely resembling the female claripes in form, but the sculpture of the clypeus and cheeks as in the maxima. Head similarly colored, but the thorax dark brown, except the pronotum and mesosterna, which are dull ivory yellow, spotted with brown; gaster dark brown with only the anterior and posterior borders of the segments and the anterior surface of the first segment ivory yellow, the latter with brown spots. Wings long $(12 \mathrm{~mm}$.), distinctly infuscated, and as in the typical claripes, with resin-brown veins and pterostigma.

South Australia: Mt. Lofty, type locality (Wheeler)

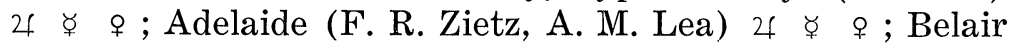
(J. W. Haacke) $\circ$.

Victoria: Sea Lake and Ultima (J. C. Goudie) $24 \quad \checkmark$.

New South Wales: The Creel, Mt. Kosciusko, $3000 \mathrm{ft}$. (Wheeler) $24 \quad \Varangle \quad q$; Jenolan Caves (J. C. Wiburd) $24 \quad \Varangle$; Katoomba (Wheeler) $2 f \quad \zeta$.

Some of these series show departures in coloration, but they are not sufficiently constant to justify distinct varietal names. Thus the maximæ from the two localities in Victoria have the gaster almost entirely dark brown, and those from Katoomba not only show considerable variation in the amount of dark brown in the gaster, but often have the en- 
tire head reddish yellow, with the exception of a median spot on the vertex.

The single mermithergate of $C$. piperatus was taken December 14, 1931, from a small colony at the Creel on Mt. Kosciusko on the same hillside as the eight consobrinus mermithergates described above. It measures $10.3 \mathrm{~mm}$. and is therefore somewhat longer than the normal maxima. The head measures $1.6 \mathrm{~mm}$., the gaster, containing a welldeveloped Mermis, $5.3 \mathrm{~mm}$. The general aspect of the specimen is that of a huge minima, but the head is distinctly broader in proportion to its length and the thorax and petiole are those of a maxima. The thorax has a distinct metathoracic sclerite and the epinotum is high, with a perceptible angle between the base and declivity. The petiolar node is robust, with a feebly notched superior border. The anterior portion of the head approaches that of the maxima in having a more uneven and more coarsely punctate surface than the minima. The color, too, is like that of the maxima, since the mesonotum and posterior portion of the epinotum are dark brown. The gaster is very pale even at the tip; the brown spots are pronounced on the pronotum, but pale and scattered on the gaster. Except for the smaller and narrower head, the specimen might be said to resemble a media, but this subcaste, as previously stated, does not seem to exist in claripes.

Camponotus (Myrmothrix) abdominalis Fabr. subsp. stercorarius Forel (Fig. 3)

C. abdominalis is a common and very aggressive, neotropical ant, quite as variable and widely distributed as the two Australian species above noticed. It ranges from southern Florida and Texas to southern Brazil as a "Formenkreis" embracing no less than 13 subspecies and 5 varieties. Most of these forms nest in moderately large colonies in dead branches or rotten wood, but some of them live, at least temporarily, in the ground under stones. This is true of the subspecies floridensis Buckley of Florida and the Central American and Mexican stercorarius. Forel (1884) long ago described the nesting habits of the latter 
from observations made by Stoll in Guatemala as follows: "This race is abundant in Central America. Mr. Stoll found it and varieties transitional to esuriens very common in the environs of Guatemala City and Antigua (cities at an altitude, with cool climate), making its nest in dry cowdung and often also under stones. Mr. Stoll has also found small
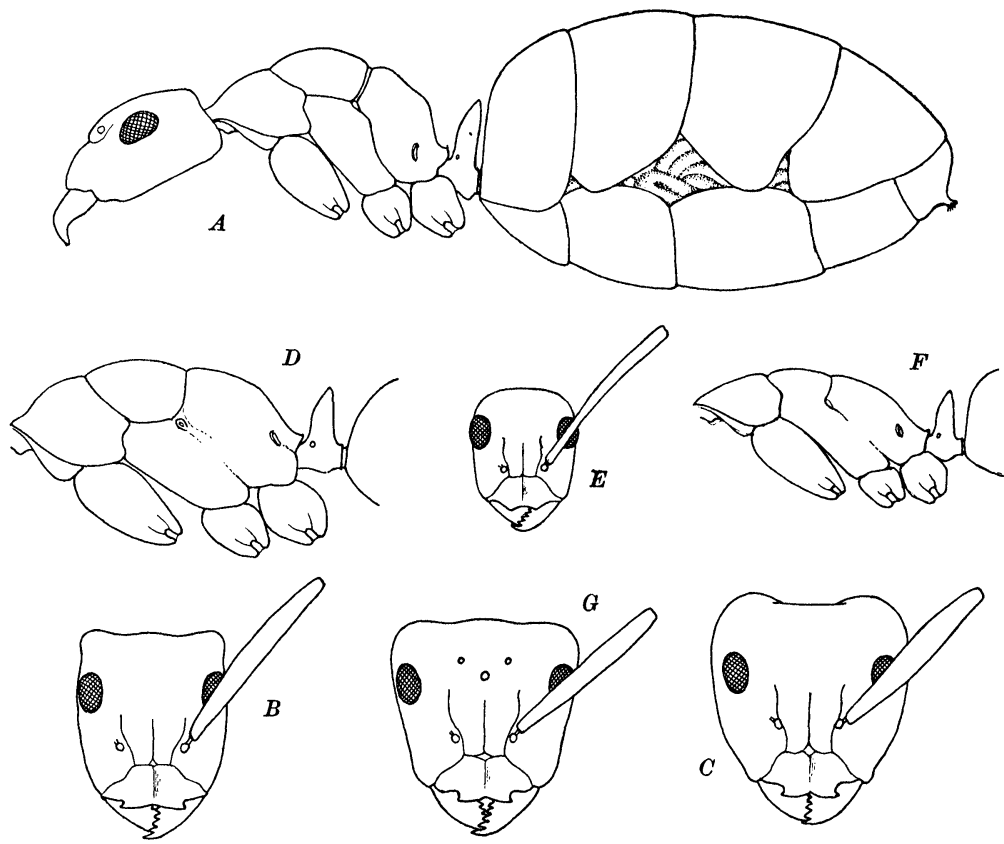

Fig. 3. Camponotus (Myrmotbrix) abdominalis Fabr. subsp. stercorarius Forel. $A$, mermithergate, in profile; $B$, head of same, dorsal view; $C$, head of worker maxima, dorsal view; $D$, thorax and petiole of same, in profile; $E$, head of worker minima, dorsal view; $F$, thorax and petiole of same, in profile; $G$, head of female, dorsal view.

formicaries of $C$. stercorarius established in the large dried fruits of Lucuma mammosum that had fallen to the ground. These fruits have a hard rind $15 \mathrm{~cm}$. long enclosing a soft pulp and a hard pit 7 to $8 \mathrm{~cm}$. in length. The ants with their larvæ and cocoons simply occupied the cavity of the fruit from which they had probably removed the pulp." 
An interesting mermithergate of stercorarius was sent me, with a portion of the colony in which it was living, by Dr. Wolfgang von Hagen, who took it during September, 1932, in the state of Guerrero, Mexico. It differs from the mermithergates of consobrinus and piperatus in being more clearly a modified maxima with some of the characters of the female. Though smaller and narrower, the head combines the characters of these two castes as shown by its sculpture, the shape of the antennæ, mandibles, clypeus, frontal carinæ, etc. The normal maxima measures 12-13 $\mathrm{mm}$., its petiole and gaster 4-4.5 mm., its head, including the mandibles $4.6 \times 3.5 \mathrm{~mm}$. The normal female is 14-15 $\mathrm{mm}$. long, the gaster and petiole $6.5 \mathrm{~mm}$., the head $3.5 \times 3$ $\mathrm{mm}$. The corresponding measurements of the mermithergate are: total length (in alcohol) $15 \mathrm{~mm}$.; gaster and petiole $7 \mathrm{~mm}$.; head $3.5 \times 2.5 \mathrm{~mm}$. Its head is decidely longer than broad, nearly as broad in front as behind, with rather straight subparallel sides, the posterior border less concave than in the maxima, the posterior corners rectangular as in the female, but with a distinct transverse impression on each side just behind the eye. This impression is absent in all the normal female castes. Eyes larger, more convex and situated more laterally when the head is viewed from above than in the maxima and therefore more like those of the female. There are no traces of ocelli. Mandibles convex like those of the maxima, with coarse teeth, but the terminal tooth is longer, as in the female. Antennal scapes stout and distinctly flattened distally as in the large media, maxima and female, extending half their length beyond the posterior border of the head (in the maxima less than $1 / 3$, in the female about $2 / 5$ ). Clypeus shaped as in the maxima, carinate, but with the anterior lobe shorter though angularly excised in the middle and strongly toothed at each lateral corner. Thorax also like that of the maxima, but smaller, shorter and somewhat more convex in the mesonotal region, with more sloping base to the epinotum. Metanotal sclerite very short as in the maxima but more distinct owing to the more pronounced mesoëpinotal impression. Petiole decidedly larger and broader than in the maxima, its superior border dis- 
tinctly notched in the middle, so that it is very similar to the petiole of the female. Gaster very large and swollen, even larger than in the virgin female, with the dorsal sclerites more or less separated, revealing the coils of one or more Nematodes through the tense intersegmental membrane. Legs longer than in the maxima, median and hind femora more slender. Sculpture, pilosity and color as in the maxima but the sides of the pro- and mesonotum with some coarse elongate grooves which are found neither in any of the normal worker forms nor in the female. Similar but finer, parallel grooves occur on the dorsal sclerites of the three first gastric segments. Traces of these grooves occur, however, on the first gastric segment of some maximæ and on the first and second segments of the female.

The thirteen known mermithergates, representing five species of Camponotus, namely the three above described, C. (Tanæmyrmex) punctulatus Mayr subsp. minutior Forel of the Argentine and $C$. (T.) pompeius Emery subsp. cassius Wheeler of the Congo, are all very similar, if we omit the last, which is merely a parasitized worker minima. Each of them exhibits a combination of worker maxima, worker minima and queen characters in the structure of the head, thorax, petiole and appendages, and may be said, therefore, to represent a pathological "intercaste" produced by Mermis infestation. The queen characters are less pronounced in the mermithergates of Camponotus than in those of Pheidole, which may even possess small ocelli. The late Dr. N. A. Cobb showed that the young Nematodes enter the body-cavity of the ant-larva. They probably undergo little growth or development till the larva is well advanced, but the disturbance they set up in the prepupal and pupal development of the host suffices to bring about a considerable diminution in the size of the head and thorax and a simultaneous greater differentiation of the latter region in the imaginal ant. The series of nine mermithergates of C. consobrinus probably arose from a series of larvæ that were, when attacked by the Mermis, at various points on the road to development as normal media and maxima workers or had even begun to develop as queens. 

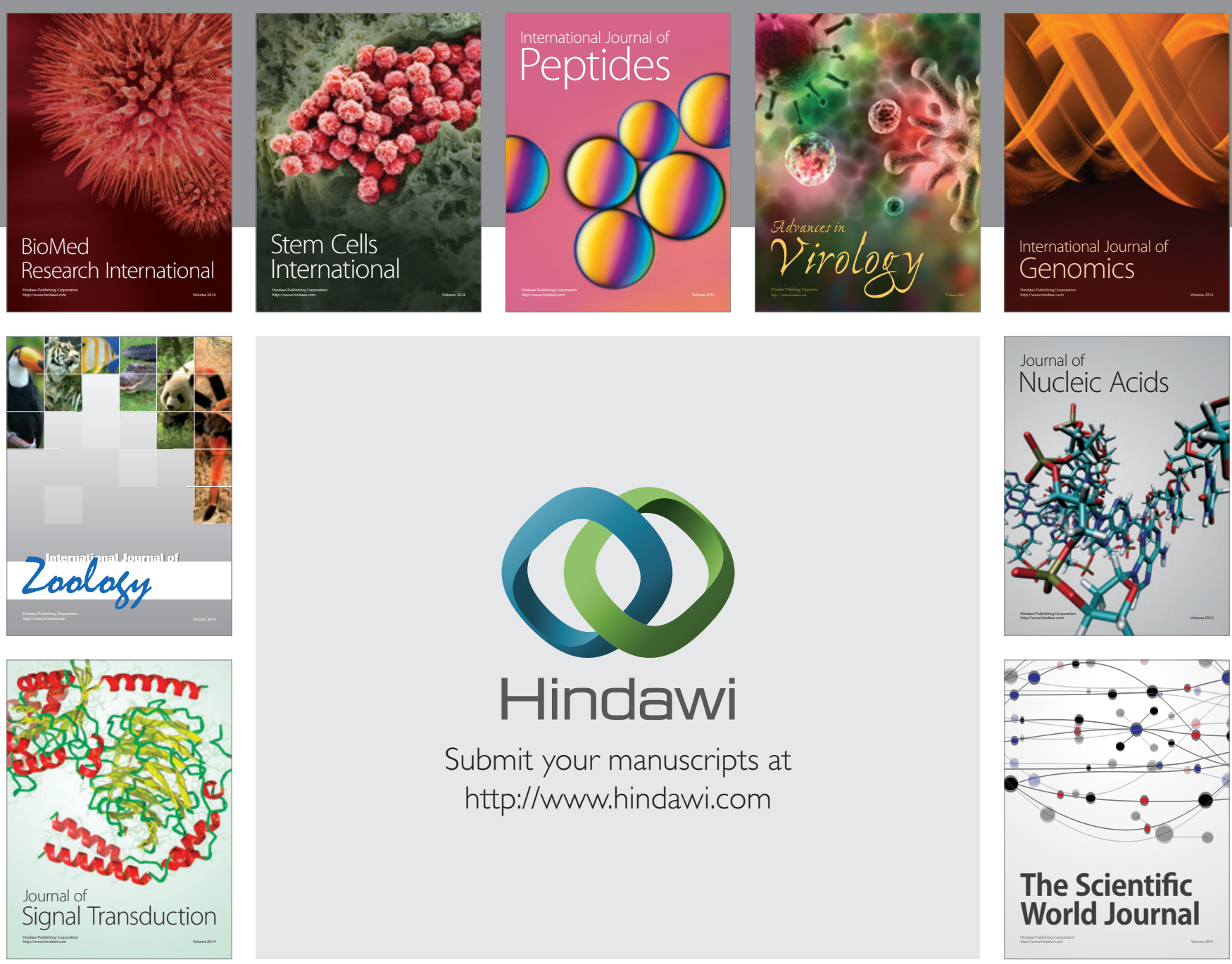

Submit your manuscripts at

http://www.hindawi.com
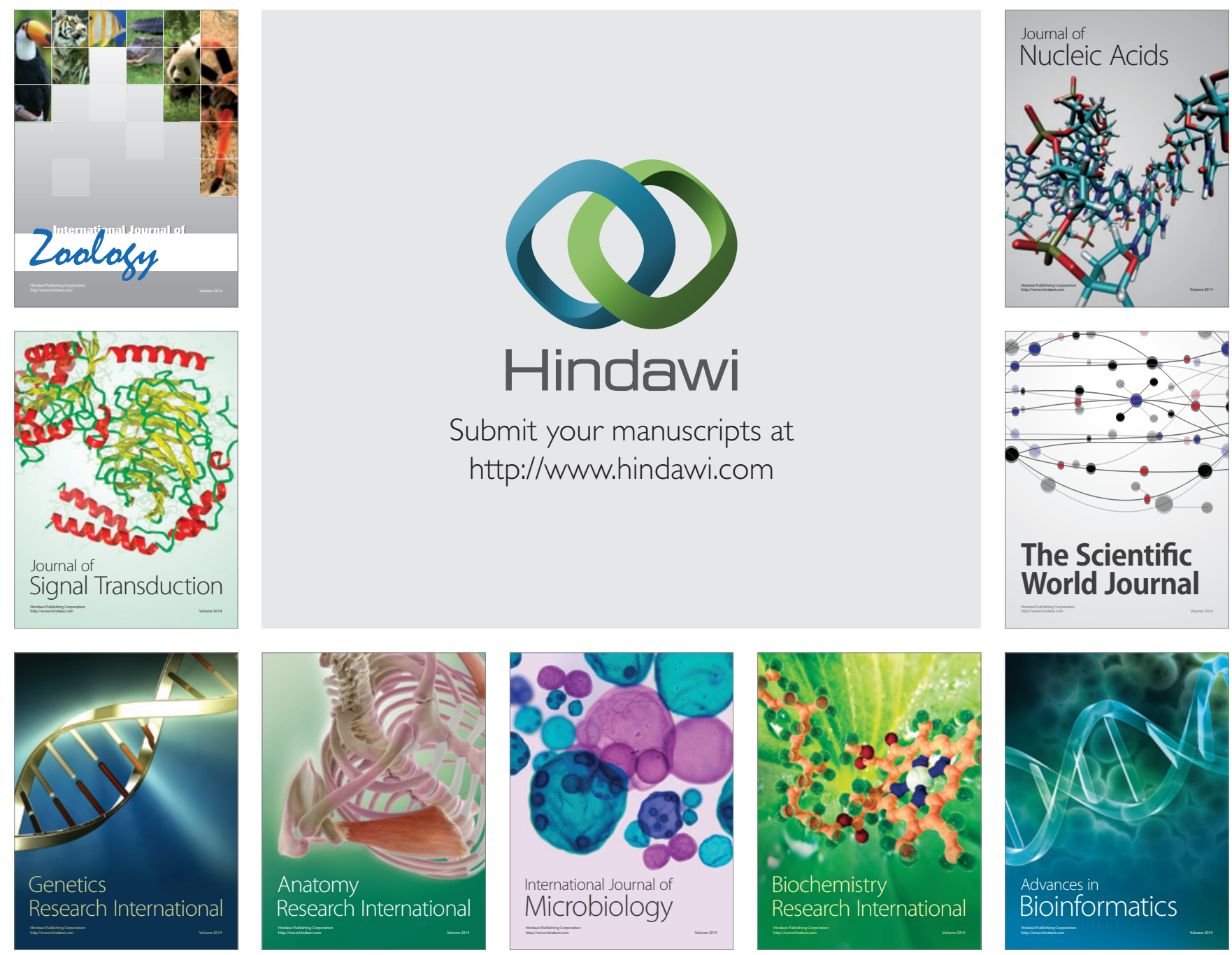

The Scientific World Journal
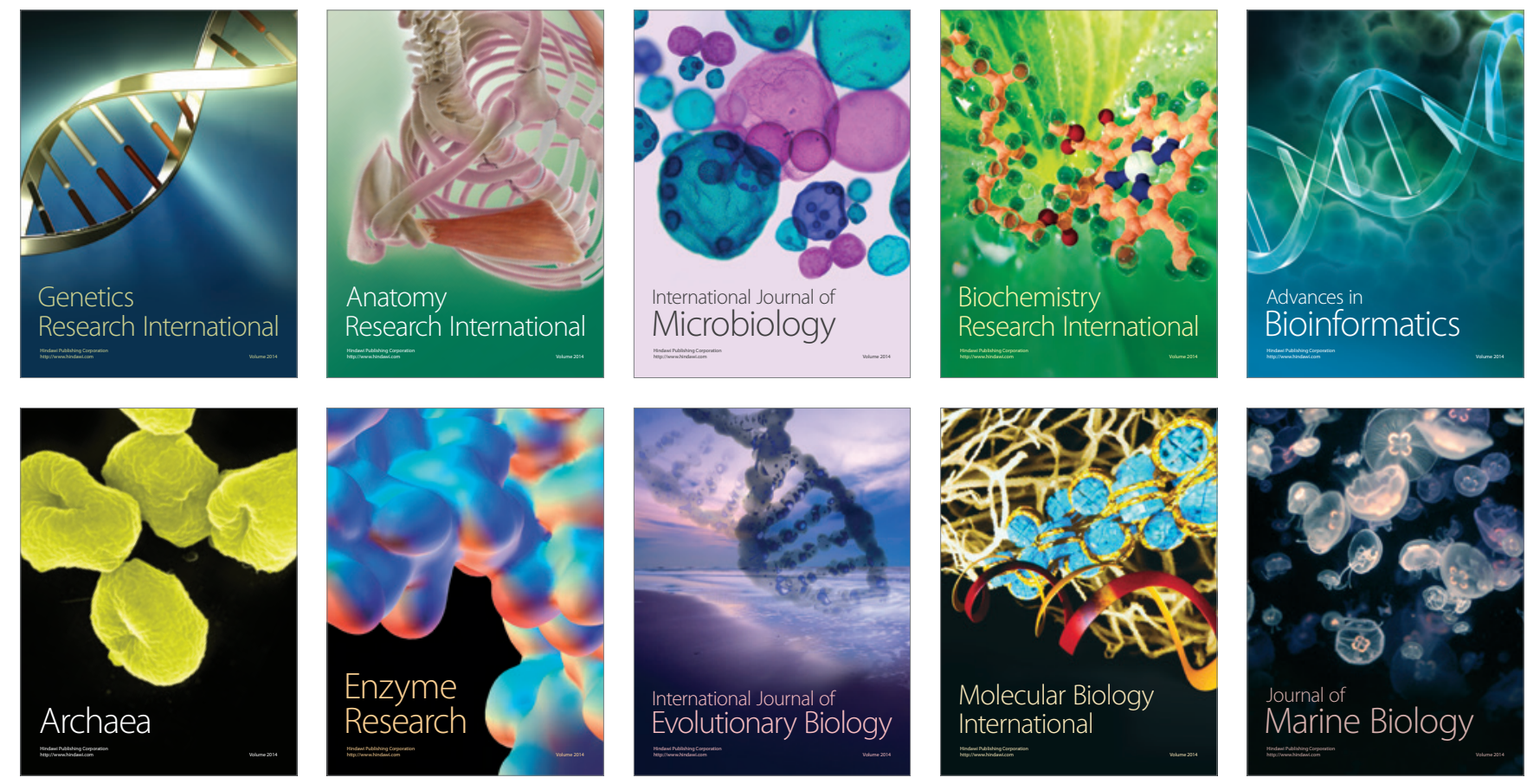